\title{
NEW DINOSAUR DISCOVERIES FROM THE LATE CRETACEOUS OF MADAGASCAR: IMPLICATIONS FOR GONDWANAN BIOGEOGRAPHY
}

SAMPSON*, Scott D., Dept. Anat., New York Coll. Osteopathic Med., Old Westbury, NY 11568; FORSTER, Catherine A., Dept. Anat. Sci., State Univ. New York, Stony Brook, NY 11794; KRAUSE, David W., Dept. Anat. Sci., State Univ. New York, Stony Brook, NY 11794; DODSON, Peter, Dept. Animal Biol., Univ. of Penn., Philadelphia, PA 19104; RAVOAVY, Florent, Service de Paleont., Univ. d'Antananarivo, Antananarivo, Madagascar.

Recent joint S.U.N.Y. Stony Brook-Université d'Antananarivo expeditions have recovered abundant, exquisitely preserved dinosaurian remains from the Upper Cretaceous (Campanian) Maevarano Fm., Mahajanga Basin, northwestern Madagascar. Prior to 1993, only three species of dinosaurs were recognized from this region, all based on isolated, fragmentary remains: Titanosaurus madagascariensis, a titanosaurid sauropod, Majungasaurus crenatissimus, a large non-avian theropod, and Majungatholus atopus, a purported pachycephalosaurid.

The recent finds demonstrate the occurrence of at least two species of titanosaurid sauropods. One specimen consists of an $80 \%$ complete skeleton including associated skull elements, making it the most complete titanosaurid yet discovered. Referral of any Malagasy sauropod materials to T. madagascariensis, however, is questionable. Relatively abundant theropod remains have also been recovered, including additional elements of Majungasaurus that support its referral to Abelisauridae. Discoveries of other previously unknown taxa include remains of a small non-avian theropod and at least three taxa of avian theropods (i.e. birds), the first avian skeletal remains from the Mesozoic of Gondwana outside of South America, Australia, and Antarctica.

Two field seasons in the Mahajanga Basin have failed to produce any further evidence of Majungatholus, and reassessment of the holotype suggests that assignment to the Pachycephalosauridae may be incorrect. This reassessment would remove the only Gondwanan occurrence of pachycephalosaurids. No remains of any ornithischian dinosaur were recovered in either field season.

Dinosaurs and other vertebrates have great potential to elucidate issues surrounding fragmentation of Gondwana. To date, however, dinosaur faunas of the southern hemisphere are poorly known. Recent and ongoing field projects are beginning to fill this gap and increase our ablily to test specific hypotheses relating to the biogeographic history of Gondwana. For example, the latest geophysical models indicate that IndoMadagascar separated from Africa 150-160 Ma., followed by the isolation of Madagascar from the Indian subcontinent 85-90 Ma. If true, Late Cretaceous faunas from Madagascar should share greater similarities with coeval faunas from India than with those from Africa. The new discoveries from the Mahajanga Basin will provide critical data for testing this and other related hypotheses. 